\title{
EUDEMONISMO Y LIBERTAD EN LA FILOSOFÍA MORAL DE LUDWIG FEUERBACH
}

\author{
Joaquín Gil Martínez ${ }^{1}$
}

\begin{abstract}
Resumen:
El trabajo filosófico de Ludwig Feuerbach es conocido, principalmente, por su crítica religiosa y filosófica, la cual, a su vez, asienta las bases de su característica antropología filosófica. En este sentido, la antropología feuerbachiana viene definida principalmente por los conceptos de Gattungswesen y Sinnlichkeit, los cuales denotan el carácter eminentemente relacional y sensible del ser humano. Teniendo esto en cuenta, el objetivo del presente trabajo es presentar la filosofía moral de Feuerbach desde la perspectiva eudemonista que la caracteriza a partir de la concepción antropológica sobre la que se sustenta, definida por el principio de Sinnlichkeit. En este sentido, la categoría fundamental de la propuesta ética de Feuerbach radica en el impulso de felicidad, definido ante todo en términos sensibles y de reciprocidad. Así mismo, el trabajo reflexiona sobre las implicaciones del eudemonismo y sensualismo con respecto a la libertad humana y su conciliación con la determinación natural que se deriva de la antropología feuerbachiana.
\end{abstract}

Palabras clave: Impulso de felicidad, Sinnlichkeit, moralidad, libertad, alteridad

\begin{abstract}
:
ThephilosophicalworkofLudwigFeuerbachisknownprimarilyforitsreligiousandphilosophicalcriticism, which, in turn, laysthefoundationof hisphilosophicalanthropology. In thissense, feuerbachiananthropology comes mainlydefinedbytheconcepts of GattungswesenandSinnlichkeit, which denote theeminentlyrelational and sensitivenature of human beings. Withthis in mind, theaim of thispaperis to presentFeuerbach's moral philosophyfromitseudemonisticperspective, whichisbasedonananthropologicalconceptionthat comes mainlydefinedbytheprinciple of Sinnlichkeit. In thissense, themaincategory of Feuerbach'sethicalproposallies in thevery idea of a drive-to-happiness, definedprimarily in terms of sensitiveness and reciprocity. Likewise, thepaperreflectsontheimplications of eudemonism and sensitivenessregarding human freedom and thepossibility of itsreconciliationwiththe natural determinationderivedfromFeuerbach'santhropology.
\end{abstract}

Keywords: Drive to happiness, Sinnlichkeit, morality, freedom, otherness

\section{Introducción}

Conviene hacer notar, como punto de partida, que Feuerbach, salvo en su período filosófico de madurez, no escribió nunca una ética ni un tratado sistemático sobre cuestiones éticas. Ahora bien, a pesar de que ello, lo cierto es que a lo largo de su producción filosófica pueden rastrearse los elementos constitutivos que acabarán

\footnotetext{
${ }^{1}$ Doctor en Filosofía. Profesor en el Departamento de Filosofía y Sociología de la Universitat Jaume I de Castellón (España).E-mail: gilj@uji.es
} 
formando su filosofía moral; en toda ella, de hecho, se encuentran ya esbozadas y señaladas algunas de las principales ideas que, ciertamente, no desarrollará hasta sus obras del último período, en especial en la Theogonie (1857), en ÜberSpiritualismusundMaterialismus (1866) y en su tratado sobre Der Eudämonismus (1869).

Al igual que la crítica de Feuerbach al contenido especulativo de la religión y la filosofía puede ser entendida, acertadamente, desde su dimensión antropológica, así también la reflexión antropológica de Feuerbach implica, en todo momento, una reflexión ética. Feuerbach, recordemos, reduce antropológicamente la dimensión religiosa del ser humano, el cual viene definido por una serie de impulsos sensibles y genéricamente compartidos que, a su vez, encarnan la realidad humana en la naturaleza y finitud del ser (cf. GIL MARTÍNEZ, 2009). Es por ello que, para Feuerbach, tales impulsos definen la esencia humana misma, la cual se manifiesta necesariamente de modo sensible, finito e individual en virtud del principio de individuación que impone la Sinnlichkeit. Tales impulsos genéricamente compartidos, además, serán los que nos posibilitan juzgar y actuar moralmente y reconocer a los demás como fin en sí mismos. Esta capacidad de actuación moral y reconocimiento de la alteridad, en definitiva, se da, según la perspectiva feuerbachiana, por compartir todos los individuos que componen el género humano una misma condición esencial; pero no se trata ya de una dimensión moral que se da mediada por el pensamiento abstracto y especulativo, sino necesariamente de modo previo a toda reflexión, es decir, desde la inmediata conciencia sensible que impone el principio de Sinnlichkeit.

Esta dimensión de impulsos constitutivos de la humanidad en virtud de la cual se fundamenta de modo inmediato la dimensión moral del ser humano, en los escritos sobre ética de Feuerbach, viene definida, en último término, por el impulso de felicidad (Glückseligkeitstrieb). En este sentido, la Theogoniese caracteriza, precisamente, por introducir por primera vez la noción de este impulso de felicidad como principio antropológico y, consecuentemente, ético. Desde esta perspectiva, la propuesta ética de Feuerbach desarrollada en sus últimos escritos, al fundarse precisamente en una comprensión naturalista-antropológica cuyo principio es el de felicidad, permite, con motivo, ser entendida como una ética materialista-eudemonista. Las siguientes líneas, por tanto, tratarán de reflexionar, en primer lugar (1) sobre el papel del impulso de felicidad en la filosofía moral de Feuerbach. A continuación (2) se verá las implicaciones del eudemonismo feuerbachiano en relación con el concepto mismo de

\begin{tabular}{|l|l|l|l|l|}
\hline Rovista Dialectus & Ano 2 & n. 6 & Janeiro - Agosto 2015 & p. 60-74 \\
\hline
\end{tabular}


libertad. Finalmente, (3) se establecerá algunas breves reflexiones sobre los límites y alcance de la ética feuerbachiana.

\section{Glïckseligkeitstrieb como principio de la moral}

Feuerbach considera en su obra de madurez la felicidad como contenido y principio de la moral $\mathrm{y}$, en este sentido, frente a la tradición del formalismo deontológico kantiano, formula una clara crítica que recuerda en sus términos a la crítica hegeliana, afirmando, de hecho, que "la filosofía de Kant, especialmente su moral, es una forma simple sin materia" (FEUERBACH, 1961a, p. 291) que prescinde, justamente, del contenido necesario y primero desde el cual, en su opinión, debe derivarse toda concepción moral, esto es, el impulso de felicidad. Frente a la promesa kantiana de una felicidad postergada, situada en segundo plano con respecto al puro deber, Feuerbach estima, al contrario, que la felicidad ha de preceder como condición de posibilidad a la virtud moral:

El hombre no debe ser bueno para ser feliz, ¡no!, más bien debe ser feliz para ser bueno, pues el hombre no puede ser bueno si, antes, no es feliz o dichoso. El ser bueno depende del bienestar. La moral que únicamente tiene que ver con los conceptos, quiere hacer dependiente a la felicidad de la virtud; pero la vida, donde se dirimen no los conceptos sino las esencias, las esencias que sienten, desean y necesitan, ella [la vida], actúa al contrario, y con razón [...] La virtud que no procede de la felicidad es únicamente hipocresía. Por tanto, quien quiera hacer mejor a los hombres, que los haga, ante todo, felices; si esto es imposible, desiste entonces también de aquello. (FEUERBACH, 1960, p. 322).

Es decir, para Feuerbach una moral fundada en meros conceptos a priori no corresponde con la realidad de la vida, esencialmente sensible y experiencial, la cual sólo puede ser virtuosa cuando, previamente satisface su impulso de felicidad. Sin embargo, lo que Feuerbach hace con una afirmación tal debe ser entendido como una llamada de atención sobre las condiciones materiales de vida. De hecho, en parte reconoce que, efectivamente, "no existe felicidad sin virtud", pero también lo contrario es cierto, que "no hay tampoco virtud alguna sin felicidad" pues ésta, la virtud, "necesita tanto como el cuerpo de alimento, luz, aire y espacio" (FEUERBACH, 1961a, p. 266). Con ello, reacciona, de hecho, contra la realidad europea de la época inmersa en

\begin{tabular}{|c|c|c|c|c|}
\hline Revista Dialeotus & Ano 2 & n. 6 & Janeiro - Agosto 2015 & p. $60-74$ \\
\hline
\end{tabular}


pleno proceso de revolución industrial, en la que las condiciones materiales de vida de las clases populares y obreras eran ínfimas:

Donde los hombres están tan apretados unos contra otros como en las fábricas inglesas y en los hogares de los trabajadores -si tales pocilgas puede llamarse hogares-; donde el oxígeno no les es distribuido en suficiente cantidad [...], allí la virtud más elevada es sólo monopolio de los señores propietarios de las fábricas. Donde falta lo necesario para vivir, allí falta también la necesidad ética. El fundamento de la vida es también el fundamento de la moral. Allí donde ante el hambre, ante la miseria, no tienes ninguna sustancia en el cuerpo, no tienes tampoco en tu cabeza, en tus sentidos y corazón ningún fundamento y sustancia para la moral [...] ¡Si queréis, por tanto, proporcionar a la moral una entrada, entonces, lograd antes que nada retirar los obstáculos materiales que obstruyen su camino! Todo lo que está en contradicción con la felicidad necesaria, con la vida humana, está también en medio del camino de la virtud y en contradicción con ella. (Ibidem, p. 267).

Este reconocimiento de las condiciones materiales como elemento necesario para la virtud moral, por tanto, prescinde de la concepción del "arrogante imperativo categórico impuesto desde el punto de vista de la filosofía abstracta” (Ibidem, p. 289) para, en su lugar, fundamentar la moral en la propia capacidad sensorial humana, la cual obliga al ser humano, a su vez, a reconocer a los demás como esencias así mismo sensibles y sintientes, y ello no sólo desde una dimensión meramente física sino, en virtud del principio de Sinnlichkeit, también espiritual. El concepto del cuerpo mismo expresa, de hecho, mucho más que un mero organismo físico o un sistema biológico, ya que constituye también el soporte relacional, intersubjetivo e histórico-socialmente mediado sobre el que se construye la propia conciencia humana y, en consecuencia, donde se inserta el origen de la moral no sólo pensada, sino también vivida.

De hecho, la afirmación por parte de Feuerbach del impulso de felicidad como el principio y contenido necesario de la dimensión moral del ser humano se basa, precisamente, en esta encarnación y sensualización de la humanidad, así como en la antropologización y fundamentación de la moral en el contenido esencial del ser humano. Esta dimensión antropológica, ya desde Das Wesen des Christentums, había sido caracterizada como un conjunto de "fuerzas" o instintos -razón, amor, voluntad, perfectibilidad- que impelían al ser humano a una realización plena (FEUERBACH,1974, p. 31). Entre estos impulsos realizativos de la humanidad, el de felicidad, de hecho, llega a revelarse ahora como el impulso primario y originario al considerar Feuerbach que "todo lo que forma parte de la vida" constituye y "forma parte del impulso de felicidad [...]; pues vida e instinto de felicidad son en sí y

\begin{tabular}{|l|l|l|l|l|}
\hline Gevista Dialectus & Ano 2 & n. 6 & Janeiro - Agosto 2015 & p. 60-74 \\
\hline
\end{tabular}




\section{EUDEMONISMO Y LIBERTAD EN LA FILOSOFÍA MORAL...}

Joaquín Gil Martínez

originariamente uno" (FEUERBACH, 1961a, p. 239). Es decir, el impulso de felicidad aglutina y contiene en su seno la totalidad de disposiciones y fuerzas naturales definitorias del ser humano en tanto que ser sensiblemente existente, de modo tal que "donde no hay ningún impulso de felicidad, no hay tampoco instinto ni impulso alguno. El impulso de felicidad es el impulso del impulso" (FEUERBACH, 1961b, p. 108). Resulta, así, que todo aquello que impele al ser humano a actuar en el mundo sensible en que se halla inserto y a llevar a cabo sus disposiciones naturales, tanto en su dimensión física como moral, ha de encontrar, a su vez, su fundamento en el propio impulso de felicidad.

El impulso de felicidad, por tanto, constituye para Feuerbach tanto el contenido como el motor originario de las facultades esenciales del ser humano. En tanto que fuerza originaria, el impulso de felicidad dota a su vez de contenido al resto de sus disposiciones naturales, genéricamente compartidas. Ahora bien, este carácter genéricamente compartido de las disposiciones naturales y del impulso de felicidad existente en toda naturaleza sensible, impone paralelamente la consideración del mismo como principio de una ética eudemonista con pretensiones de validez universal, en tanto que válido para todo ser humano por hacer referencia, precisamente, al ser esencial de la humanidad. Esta noción del impulso de felicidad en calidad de "fuerza", es decir, como motor y principio constitutivo de la moralidad, indica, no obstante, que su contenido está aún por realizarse.

Consecuentemente, el carácter universal de la ética propuesta por Feuerbach, en tanto que fundada en su concepción antropológica, bien podría ser comparada con la noción desarrollada por José Luis Aranguren a partir del pensamiento de Zubiri de una "moral como estructura" antropológicamente compartida, la cual, sin embargo, debe aún ser dotada de contenido (ARANGUREN, 1981, p. 50). En cualquier caso, esta noción de la "moral como estructura" -que en Feuerbach queda constituida por medio del impulso de felicidad-, si bien parece que podría participar de ciertos planteamientos formalistas, no puede, sin embargo, confundirse con el formalismo deontológico ante el cual, de hecho, se opone Feuerbach de modo explícito, sino, como mucho, ser entendido como cierto formalismo agathológico, es decir, aquel referido, precisamente, a la estructura antropológica.

Por otro lado, el impulso de felicidad mismo, en virtud de su origen sensual y sensible -y en ello radica la especificidad de la filosofía moral de Feuerbach- es el que dota a su vez de contenido concreto a dicha estructura moral. El impulso de felicidad

\begin{tabular}{|l|l|l|l|l|}
\hline Rovista Dialeatus & Ano 2 & n. 6 & Janeiro - Agosto 2015 & p. 60-74 \\
\hline
\end{tabular}


constituye así tanto la forma -en su calidad de impulso constitutivo del ser humanocomo el contenido de la moralidad. Contenido, además, que se encuentra siempre, en la perspectiva de Feuerbach, socialmente mediado.

En este sentido, bien es cierto que una concepción ética basada en un eudemonismo con pretensiones de universalidad no puede prescindir de un concepto de justicia, a la vez que necesita, diferenciar entre diversos grados de felicidad y de la utilización, para ello, de conceptos como naturaleza humana o mínimo natural, conduciendo así a la teoría hacia bases psicológicas o antropológicas. Tal es el caso, precisamente, de la filosofía moral de Feuerbach. Ésta, por lo demás, no se agota en el concepto de Sinnlichkeit y en las fuerzas y disposiciones naturales ya mencionadas sino que, en virtud de su noción de Gattungswesen, determina al ser humano como un ser esencialmente relacional. Esta noción del carácter relacional de la humanidad, en virtud tanto de la idea de un ser y esencia genéricos como del principio de sensualidad esespecialmente relevante a la hora de encontrar el fundamento de la moral desde la perspectiva feuerbachiana.

De hecho, si partimos del carácter esencialmente relacional del ser humano y de la necesidad de establecer vínculos con la alteridad que, en sí mismos, obligan en la relación interpersonal (CORTINA, 2007, p. 41), entonces tales vínculos provienen, en el caso de la filosofía moral de Feuerbach, precisamente, de su concepción antropológica en tanto que definida principalmente por el conjunto de disposiciones esenciales que impelen al ser humano a la relación interpersonal. Entre éstas, en la ética propuesta por Feuerbach, destaca ante todo el impulso de felicidad. Se trata éste de un vínculo que, en consecuencia, y retomando la necesidad de un concepto de justicia y una diferenciación entre distintos grados de felicidad, impone la necesidad de diferenciar, por tanto, entre una justa e injusta, buena y mala, satisfacción del impulso de felicidad, esto es, aquella entendida ante todo de un modo bilateral, comprensivo y abierto a la satisfacción también del impulso de felicidad de la alteridad:

¿¡Felicidad!?! ¡No! ¡Justicia, la Justice! Pero la justicia no es más que la felicidad mutua, bilateral, en oposición a la felicidad unilateral, egoísta o partidista del viejo mundo. (GRÜN, 1874, p.320).

Así pues, para Feuerbach la satisfacción del impulso de felicidad propio, de hecho, no puede ni debe realizarse en oposición al impulso de felicidad del otro sino, más bien, en consonancia con aquél. Pues, si bien es cierto que para Feuerbach el primer

\begin{tabular}{|l|l|l|l|l|}
\hline Ronista Cialeatus & Ano 2 & n. 6 & Janeiro - Agosto 2015 & p. 60-74 \\
\hline
\end{tabular}


deber es hacerse feliz a uno mismo, esto es, posibilitar "el estado de bienestar y perfección" (FEUERBACH, 1961a, p. 231), la adquisición de tal estado no puede ir en contra de aquello que es su condición de posibilidad, esto es, la relación intersubjetiva y de complementación mutua en la que se realiza la totalidad de la esencia genéricamente compartida. Por ello, afirma Feuerbach:

[...] la moral no conoce ninguna felicidad sin felicidad ajena, no conoce ni quiere conocer ninguna felicidad aislada, separada o independiente de la felicidad del otro, o fundamentada con conocimiento y voluntad en su infelicidad; $[\ldots]$ conoce sólo una felicidad común, sociable. (Ibidem, p. 273).

En definitiva, para Feuerbach la justicia y el deber moral encuentran su raíz no en conceptos a priori de la razón abstracta sino, más bien, en la propia razón sintiente, sensible, que define al ser humano en su totalidad, consistiendo la acción moral misma -siempre en referencia a los demás- en nada más que potenciar, impulsar y aventurar el mismo impulso de felicidad que yo, a mí mismo, no me puedo negar en tanto que ser sensible. En este sentido, afirma Feuerbach de forma clara que "la felicidad propia no es, evidentemente, finalidad y fin de la moral, pero sí su fundamento y presupuesto" (Ibidem, p. 275) pues, tal y como reza la Regla de Oro de toda concepción ética, para saber qué debo hacer o no hacer en referencia a los demás, necesito previamente conocer aquello que es bueno o malo para mí mismo, de modo tal que, desde la perspectiva eudemonista de Feuerbach, "no tenemos ningún otro origen de lo que es bueno o malo [...] más que los deberes hacia nosotros mismos. Bueno es lo que está conforme con el impulso de felicidad humano; malo, lo que le contradice con conocimiento y voluntad" (Ibidem, p. 275).

El impulso de felicidad humano es, por tanto, el principio y fundamento, según Feuerbach, de toda moral ya que, en virtud de éste, tanto yo como los demás estamos indisociablemente vinculados, siendo la tarea de la moral, por tanto, la de convertir en ley del pensamiento y de las acciones humanas el nexo antropológicamente fundamentado entre la felicidad propia y la ajena, y ello, además, "con conocimiento y voluntad" pues el carácter intencional, de hecho, no desaparece en la filosofía moral feuerbachiana.

\section{Sinnlichkeit, libertad y felicidad}

\begin{tabular}{|l|l|l|l|l|}
\hline Revista 2 ialectus & Ano 2 & n. 6 & Janeiro - Agosto 2015 & p. 60-74 \\
\hline
\end{tabular}


En el desarrollo filosófico de Feuerbach, el concepto de Sinnlichkeit, tal y como se ha mostrado, adquiere una importancia sustancial hasta el punto tal de incidir plenamente en su concepción ética entendida, principalmente, desde una perspectiva eudemonista. No es de extrañar, consecuentemente, que también la naturaleza ocupe un lugar central en el desarrollo de su última filosofía, lo cual revela la amplitud significativa que este término -Sinnlichkeit- guarda en su seno. De este modo, en 1846, e influido por la teología del sentimiento de Schleiermacher, Feuerbach se ve impulsado a matizar y ampliar el sentido y significado de su filosofía con las siguientes palabras:

Si yo sinteticé una vez mi enseñanza en la frase: la teología es la antropología, debo añadir como complemento: y fisiología. Mi enseñanza o intuición se resume, así pues, en dos palabras que se implican mutuamente: naturaleza y hombre. La esencia que yo tengo, por supuesto, del hombre [...], que es su causa o fundamento, a la que éste debe su nacimiento y existencia [...], la llamo yo naturaleza, una esencia y palabra [...] sensibles. Pero a la esencia en la que la naturaleza llega a ser un ser personal, consciente, intelectual [...], la llamo el hombre. El ser carente de conciencia de la naturaleza es para el ser eterno, inoriginado, el ser primero, pero primero en el tiempo, no en el rango; el ser primero física, pero no moralmente; el ser humano consciente es para mí lo segundo surgido en el tiempo, pero el primer ser por el rango. (FEUERBACH, 1969, p. 28).

Con semejante declaración, en la que el ser consciente -y por tanto moral- es presentado como algo cualitativamente nuevo con respecto a lo meramente físico, se sitúa Feuerbach de forma clara en contra del materialismo reduccionista, si bien es cierto que la filosofía moral del último Feuerbach puede ser calificada, con motivo, como materialista. Él mismo reconocería que "el materialismo es el único fundamento sólido de la moral" (FEUERBACH, 1961b, p. 151), aunque este materialismo postulado por Feuerbach es de un tipo especial: ciertamente reconocimiento de la naturaleza como todo sensible y determinante de la realidad, pero, ante todo, materialismo antropológico.

Efectivamente, Feuerbach deriva toda la moralidad del ser esencial del "hombre real", del hombre tal y como existe. Éste, en cuanto tal, se halla atravesado radicalmente por el principio de la Sinnlichkeit, de forma tal que no es sólo esencialmente pensamiento, voluntad y sentimiento, sino también corporalidad, sensibilidad, sensorialidad, sensualidad. Todas estas dimensiones son las que configuran al hombre como un ser real y, por tanto, si Feuerbach quiere poder obtener la moralidad del propio ser del hombre, entonces, necesariamente, tales dimensiones tendrán que tener

\begin{tabular}{|l|l|l|l|l|}
\hline Q Ponista Dialectus & Ano 2 & n. 6 & Janeiro - Agosto 2015 & p. 60-74 \\
\hline
\end{tabular}




\section{EUDEMONISMO Y LIBERTAD EN LA FILOSOFÍA MORAL...}

Joaquín Gil Martínez

implicaciones en la ética de Feuerbach. Dada la amplitud de significado de la Sinnlichkeit, estas implicaciones tienen, por lo demás, y de forma especial, su manifestación en el tema de la libertad en relación con la naturaleza determinante, y en la formulación de una ética materialista en sentido eudemonista.

En el primero de estos sentidos, la consideración del "hombre real" como un ser que encuentra su identidad no sólo en el espíritu sino también en su cuerpo material con todas sus determinaciones- impone la necesidad de que éste, el ser humano concreto y determinado, sea definido como un ser natural, es decir, imbuido e inmerso en la naturaleza, ya que ésta constituye "el compendio sustancial de la realidad" (FEUERBACH, 1970, p. 61). Para Feuerbach, por tanto, el ser humano, en tanto que ser natural, se encuentra determinado, imbricado con la misma naturaleza. Pero esta determinación de la naturaleza no significa en ningún caso que el individuo finito y sensiblemente determinado carezca de libertad, sino más bien al contrario. Es la propia naturaleza la que determina al ser humano como un ser atravesado por impulsos naturales -entre los que se encuentran el instinto de perfeccionamiento y el de felicidadque lo hacen libre en la medida en que posibilitan un progresivo desarrollo de las potencialidades naturalmente intrínsecas a su esencia y la superación de necesidades y constricciones temporalmente definidas.

El propio Feuerbach definía la libertad en los siguientes términos: "La libertad no consiste en otra cosa que en dotar al hombre de una esfera ilimitada en consonancia con su totalidad, con todas sus fuerzas y disposiciones" (FEUERBACH, 1961c, p. 312). En cualquier caso, la afirmación feuerbachiana del ser humano como un ser radicalmente libre cuya condición de posibilidad radica en su misma determinación natural, no significa, sin embargo, que esta libertad se dé de forma inmediata. La libertad, más bien, es algo que el ser humano debe conseguir por sí mismo, como fin y meta, a través de su voluntad natural de perfeccionamiento, en relación constante con los contextos histórico-temporales en que se inserta el individuo concreto y que determinan parte importante de sus necesidades y limitaciones. La finalidad y sentido últimos de esta realización de la libertad no es otra, pues, que la de dar contenido a la exigencia ética que impone el impulso natural del hombre a su felicidad, ya que "sólo el impulso de felicidad [Glückseligkeitstrieb] constituye el vínculo entre la necesidad y la libertad" que se conjugan y combinan en el "hombre real" (FEUERBACH, 1961b, p. 139).

\begin{tabular}{|l|l|l|l|l|}
\hline Gonista Dialectus & Ano 2 & n. 6 & Janeiro - Agosto 2015 & p. 60-74 \\
\hline
\end{tabular}


Por otra parte, los impulsos de perfeccionamiento y felicidad, estrechamente relacionados con el anhelo y ansia de la libertad, son de una fuerza tal que el ser humano fácilmente puede proponerse una determinación más allá, más alta, que la correspondiente a la disposición e impulsos naturales, de modo tal que pierda de vista aquello que efectivamente es realizable y que viene determinado, a su vez, por la propia naturaleza. Por ello, Feuerbach hace suyo el principio ético propio de los estoicos del "vivir según la naturaleza", afirmando consecuentemente la necesidad de "naturalizar la libertad" (FEUERBACH, 1970, p. 62), es decir, de asentarla en su fundamento de realidad y posibilidad:

El retorno a la naturaleza es la única fuente de salvación. Es falso entender la naturaleza en contradicción con la libertad ética [...] La naturaleza se resiste contra la libertad fantástica, pero no contradice la libertad razonable. (Ibidem, p. 61).

La naturaleza, por tanto, no es sólo el fundamento de la posibilidad de libertad en el ser humano, sino también la encargada de la adecuación, el marco de referencia, de los instintos vitales y esenciales que la realizan. Estos impulsos son los ya mencionados de perfeccionamiento y felicidad, propios y característicos de esa fuerza esencial, la voluntad, que junto a la razón y al amor forman la "trinidad divina en el hombre" (FEUERBACH, 1974, p. 31). Por su parte, la voluntad, como querer, es siempre concreta, determinada por su objeto de volición, pues "querer" significa "querer algo". Efectivamente, la voluntad considerada en abstracto es simple forma necesitada de contenido, de materia que le dé significado y sentido; pero una forma tal que es esencial, que constituye parte de la esencia natural del individuo: el hombre real es volitivo por naturaleza.

Ahora bien, el carácter dependiente de la voluntad nos lleva a una compleja dinámica. La voluntad, el querer, es mera forma que necesita de un objeto de volición que la defina, siendo éste, por tanto, la verdad de la voluntad. Pero siendo la voluntad un elemento esencial del ser humano, tal objeto ha de ser, en consecuencia, un elemento adecuado a su esencia en tanto que ser natural. En este sentido, la primera determinación de la voluntad proviene precisamente de la naturaleza misma que define esencialmente al ser humano: es la naturaleza, por tanto, la que adecua el impulso de la voluntad a la capacidad del "hombre real" y la que media entre lo que es objeto de anhelo y el sujeto del anhelo. El contenido que la naturaleza otorga a la voluntad, por lo

\begin{tabular}{|l|l|l|l|l|}
\hline Revista Dialectus & Ano 2 & n. 6 & Janeiro - Agosto 2015 & p. 60-74 \\
\hline
\end{tabular}


demás, que constituye así parte esencial de las determinaciones del ser humano, no es otro que la tendencia a la felicidad. En una carta de 1863 escribe Feuerbach a Bolin:

El pensamiento fundamental de mi trabajo sobre la voluntad [se refiere a Sobre espiritualismo y materialismo] es la unidad de la voluntad y del impulso de felicidad: "yo quiero significa: yo no quiero padecer desgracia -dicho concisamente- yo quiero ser feliz". (FEUERBACH, 1964, p. 297).

Efectivamente, la tendencia a la felicidad constituye el objeto más adecuado para la voluntad en la medida en que tal tendencia, acorde con el principio de Sinnlichkeit, viene determinada por la corporalidad y sensibilidad esencial del hombre real. En la naturaleza del individuo concreto, finito y determinado, en su esencia más propia, se encuentra por tanto el impulso y la tendencia a su felicidad: "el impulso de felicidad es instinto primigenio y fundamental de todo lo que ama y vive, de todo lo que es y quiere ser" (FEUERBACH, 1961b, p. 231).

Ahora bien, ha de recordarse que Feuerbach, en el campo de la reflexión ética, ha llevado a cabo una antropologización de la moral a través de la cual el ser esencial del ser humano se convierte, a su vez, en deber-ser. Feuerbach deriva, por tanto, la moralidad a partir del individuo concreto y determinado. La felicidad del individuo particular se convierte así, en el seno de su ética materialista-eudemonista, en el fundamento, origen y causa de la distinción ética entre lo bueno y lo malo, lo justo y lo injusto:

La felicidad propia no es, evidentemente, finalidad y fin de la moral, pero sí su fundamento y presupuesto. Quien no le concede lugar ninguno en la moral y la expulsa de la misma abre las puertas a una arbitrariedad diabólica; pues sólo desde la experiencia de mi propio impulso de felicidad sé lo que es bueno o malo, lo que es la vida o la muerte, lo que es y cómo actúa el amor o el odio; por ello no le doy al hambriento piedras en lugar de pan ni al sediento ácido nítrico en vez de agua potable. (Ibidem, p. 275).

La experiencia personal, propia, subjetiva e individual, fundada en la Sinnlichkeit, se convierte de este modo en el medio a través del cual el yo concreto es capaz de abrirse compasivamente a las experiencias sensibles de felicidad y desgracia de la alteridad. La felicidad es, entonces, la categoría central de la moralidad, que encuentra su fundamentación última en el amor propio del individuo que le impele a ella, a la felicidad, a abrazar los placeres y rechazar el dolor. De este modo, y en último

\begin{tabular}{|l|l|l|l|l|}
\hline Rovista Dialectus & Ano 2 & n. 6 & Janeiro - Agosto 2015 & p. 60-74 \\
\hline
\end{tabular}


término, es en torno al amor donde gira la moralidad, pero al amor de sí, al sentimiento egoísta e individual de afirmación y voluntad de vida que es, a su vez, el fundamento de la compasión hacia el otro, el fundamento de la moralidad:

¿Pero cómo es posible desdeñar que una vez más el impulso de felicidad yace como fundamento de la compasión? ¿Que esta simpatía con el que sufre proviene de la antipatía hacia el sufrimiento, de la voluntad de no sufrir, de ser feliz; que, por tanto, la compasión sólo es el propio impulso de felicidad compasivo, co-afectado por la lesión del impulso de felicidad ajeno? Todo hombre insensible, indiferente antes su propio dolor, será también insensible al dolor de los demás. (Ibidem, p. 277).

En definitiva, la propuesta ética de Feuerbach se fundamenta en último término en el impulso de felicidad, el cual puede ser entendido, precisamente como amor propio o amor de sí, de forma tal que el amor mismo, en tanto que orientado hacia nosotros mismos, es lo que constituye, en la perspectiva de Feuerbach, el principio de la moral(cf. GIL MARTÍNEZ, 2011). Esta dimensión eudemonista de la filosofía moral de Feuerbach, centrada en el impulso de felicidad propio y personal, determina, a su vez, el contenido de la voluntad subjetiva ya que ésta, ilimitada en tanto que forma, se haya determinada, sin embargo, por el contenido concreto del sujeto voliente. Feuerbach, al llevar a cabo una reducción antropológica de la moral, considera que este contenido de la voluntad en su dimensión ética, no puede más que provenir de las propias determinaciones naturales del ser humano, esto es, del propio impulso de felicidad.

Ahora bien, este impulso de felicidad subjetivo -el amor de sí- que constituye el fundamento de la ética feuerbachiana no implica, sin embargo, un repliegamiento de la subjetividad sobre sí misma sino, necesariamente, la puesta en consonancia del impulso de felicidad propio con el impulso de felicidad ajeno. Conociendo las necesidades y requerimientos de nuestra felicidad podemos conocer y reconocer compasivamente, a su vez, las necesidades y requerimientos del impulso de felicidad ajeno, a la vez que la satisfacción de la propia felicidad sólo puede llevarse a cabo en relación y conexión con el impulso de felicidad del otro, que me complementa, y viceversa.

\section{Consideraciones finales}

La propuesta antropológica de Feuerbach, definida por conceptos tales como los de Gattungsweseny, principalmente, el de Sinnlichkeit, tienen una influencia directa en

\begin{tabular}{|l|l|l|l|l|}
\hline Q Rovista Dialectus & Ano 2 & n. 6 & Janeiro - Agosto 2015 & p. 60-74 \\
\hline
\end{tabular}




\section{EUDEMONISMO Y LIBERTAD EN LA FILOSOFÍA MORAL...}

Joaquín Gil Martínez

la formulación de su filosofía moral. Así mismo, tras su crítica al contenido especulativo de la religión y la filosofía, Feuerbach reduce antropológicamente tanto a la filosofía del absoluto como a la teología y, en consecuencia, a la moralidad en ella fundada. Al no aceptar ningún principio inmaterial de la realidad, de la naturaleza, del ser humano ni de cualquier actividad esencialmente relacionada con él, Feuerbach obtiene los valores morales, precisamente, a partir de la propia humanidad, de sus facultades esenciales entendidas como fuerzas e impulsos que posibilitan su perfeccionamiento. Esta capacidad por parte del ser humano que lo faculta como un ser susceptible de plena autonomía y libertad es, por lo demás, el primer principio de la esencia humana.

Ahora bien, la caracterización de esta esencia humana como capacidad de realización supone que ésta no se da de forma inmediata, sino que tiene que ser alcanzada por la humanidad misma, por su propia actividad. Por ser una capacidad esencial, el actualizarla se convierte, pues, en la primera exigencia ética del ser humano. Así mismo, la plena realización de la humanidad, según Feuerbach, sólo se lleva a cabo por medio de la relación intersubjetiva y comunitaria $\mathrm{y}$, por ello, las facultades esenciales que impulsan al hombre a la apertura del yo al tú y que lo capacitan para ello se constituyen, así mismo, en los elementos centrales de la filosofía moral propuesta por Feuerbach.

Entre estas determinaciones del ser-esencial de la humanidad, la sensibilidad misma, definida por el principio de Sinnlichkeit, constituye un elemento central en la concepción antropológica de Feuerbach y, consecuentemente, en su ética. En este sentido, el principio y fundamento de la moralidad es, para Feuerbach, el impulso de felicidad (Glückseligkeitstrieb) individual, que orienta al ser humano tanto a una realización de sus facultades y disposiciones como a evitar todo sufrimiento y padecimiento que atente contra su ser sensible. Ahora bien, que el principio de la moral sea este impulso de felicidad no supone que, a su vez, éste sea su finalidad, pues la moralidad de las acciones del ser humano hace referencia, siempre, a nuestras relaciones con los demás. En este sentido, la finalidad de la moralidad es, por tanto, la realización plena del yo en relación con los otros y, por tanto, la consideración de la alteridad tiene una importancia sustancial a la hora de tener en cuenta la propuesta ética de Feuerbach.

Esta mirada hacia el otro supone, por lo demás, la consideración del impulso de felicidad ajeno y la necesidad de potenciarlo y satisfacerlo, pues sólo con ello puede el individuo, en tanto que ser relacional, satisfacer a su vez su propio impulso de felicidad. Es este, pues, un impulso esencialmente compartido, relacional. Así mismo, el propio

\begin{tabular}{|c|c|c|c|c|}
\hline Q Ponista Dialectus & Ano 2 & n. 6 & Janeiro - Agosto 2015 & p. $60-74$ \\
\hline
\end{tabular}




\section{EUDEMONISMO Y LIBERTAD EN LA FILOSOFÍA MORAL...}

Joaquín Gil Martínez

impulso de felicidad determina, en la perspectiva feuerbachiana, el contenido de la voluntad humana. Ésta, ilimitada por su forma, se encuentra, así, limitada por su contenido ya que el objeto de la facultad volitiva del ser humano, en tanto que disposición natural, no puede atentar, precisamente, contra su condición de posibilidad, esto es, la naturaleza misma que impone en el ser humano el impulso de felicidad.

El problema aparente, entonces, de una ética formulada en términos feuerbachianos parecer ser, pues, en qué medida se concilia la libertad esencial de perfeccionamiento y autodeterminación de la humanidad con la determinación que impone la naturaleza sobre el ser humano en tanto que ser sensiblemente condicionado, en tanto que ser natural. Tal contradicción, en cualquier caso, no es tal si se entiende que la propia naturaleza es la que determina al "hombre real" como un ser esencialmente dotado de un impulso natural a realizarse libremente, al perfeccionamiento de sí mismo y por sí mismo, en consonancia con el impulso de felicidad de la alteridad.

La realización del ser humano como radicalmente libre, por fundarse en una capacidad esencial confirmada por la naturaleza, se convierte, en definitiva, en una exigencia ética que, sin embargo, tiene como sentido último el de satisfacer en el hombre su tendencia así mismo natural y esencial a la felicidad. La libertad y autonomía del ser humano es, por tanto, es felicitante, las cuales sólo pueden realizarse, en la perspectiva comunitaria de Feuerbach, en la relación intersubjetiva e interpersonal compartida, de modo tal que en ello radica, precisamente, según Feuerbach, el carácter esencial y ético del acceso a la libertad.

\section{Referencias bibliográficas}

ARANGUREN, J. L. Ética. Madrid: Alianza Editorial, 1981.

CORTINA, A. Ética de la razón cordial. Oviedo: Ediciones Nobel, 2007.

FEUERBACH, L. Theogonie. In: SämtlicheWerke. Vol. IX. Org. por W. Bolin y F. Jodl. Stuttgart/Bad-Canstatt: FromannVerlag, 1960.

ZurEthik: Der Eudämonismus. In: SämtlicheWerke. Vol. X. Org. por W. Bolin y F. Jodl. Stuttgart/Bad-Canstatt: FromannVerlag, 1961a.

ÜberSpiritualismusundMaterialismus in besondererBeziehungauf die Willensfreiheit. In: SämtlicheWerke. Vol. X. Org. por W. Bolin y F. Jodl. Stuttgart/Bad-Canstatt: FromannVerlag, 1961b.

\begin{tabular}{|l|l|l|l|l|}
\hline Gevista Dialectus & Ano 2 & n. 6 & Janeiro - Agosto 2015 & p. 60-74 \\
\hline
\end{tabular}


NachgelasseneAphorismen. In: SämtlicheWerke. Vol. X. Org. por W. Bolin y F. Jodl. Stuttgart/Bad-Canstatt: FromannVerlag, 1961c.

. BriefanBolin (19-05-1863). In: SämtlicheWerke. Vol. XIII. Org. por W. Bolin y F. Jodl. Stuttgart/Bad-Canstatt: FromannVerlag, 1964.

Vorlesungenüber das Wesen der Religion. In: GesammelteWerke, Vol VI. Org. por W. Schuffenhauer. Berlin: Akademie-Verlag, 1969.

ZurKritik der HegelschenPhilosophie. In: GesammelteWerke, VolIX. Org. por W. Schuffenhauer. Berlin: Akademie-Verlag, 1970.

VorläufigeThesenzurReformation der Philosophie. In: GesammelteWerke, VolX. Org. por W. Schuffenhauer. Berlin: Akademie-Verlag, 1971.

Das Wesen des Christentums. In: GesammelteWerke, Vol V. Org. por W. Schuffenhauer. Berlin: Akademie-Verlag, 1974.

GIL MARTÍNEZ, J. Claves antropológicas de la actitud crítica en Feuerbach. In: Argumentos. Revista de Filosofia, Fortaleza, n. 2, jul./dez. 2009, p. 51-60.

La dimensión materialista-eudemonista en la ética de Feuerbach. Hacia una ética basada en el amor. In: CHAGAS, E. F.; REDYSON, D. (Orgs.). Ludwig Feuerbach. Filosofia, religião e natureza. São Leopoldo: Nova Harmonia, 2011, p. 67-88.

GRÜN, K. Ludwig Feuerbach in seinemBriefwechsel und Nachlasssowie in seiner philosophischenCharakterentwicklung. Leipzig: C.F. Winter, 1874.

\begin{tabular}{|l|l|l|l|l|}
\hline Q Rovista Dialectus & Ano 2 & n. 6 & Janeiro - Agosto 2015 & p. 60-74 \\
\hline
\end{tabular}

